\title{
Infraestrutura, fazendas horizontais e pena sustentável: alternativas para aplicação do regime semiaberto
}

rdai.com.br/index.php/rdai/article/view/420

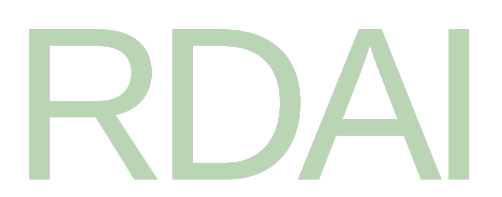

\section{Autores}

- Alexandre Coutinho Pagliarini Centro Universitário Internacional (Curitiba, Paraná, Brasil)

- Flávio Adriano Rebelo Brandão Santos Universidade Tiradentes (Maceió, Alagoas, Brasil)

- Arthur Augusto Garcia Centro Universitário Internacional (Curitiba, Paraná, Brasil)

\section{DOI:}

https://doi.org/10.48143/rdai.19.acp

\section{Palavras-chave:}

Infraestrutura, Fazenda vertical, Regime semiaberto, Meio ambiente

\section{Resumo}

Este artigo científico aborda a infraestrutura dos espaços prisionais e objetiva demonstrar novas formas de cumprimento de pena no regime semiaberto, por meio da adoção de medidas sustentáveis. Com a idealização das fazendas verticais nos perímetros penitenciários, é possível propiciar a execução da pena em um ambiente mais humanizado de efetivo trabalho, e isso estará em sintonia com a sustentabilidade ambiental, permitindo-se conciliar a execução da pena com o desenvolvimento humano sustentável, sem que isso vá de encontro com a Lei de Execuções Penais. Entende-se que uma política pública que proporcione essa nova forma de cumprimento de pena, substituindo as obsoletas colônias penais pelas fazendas verticais, permitirá ao detento o cultivo de verduras, legumes e outras atividades agrícolas, ao passo que os produtos finais desse cultivo serão revertidos para alimentação dos demais encarcerados, ou, ainda, adquiridos por atores sociais devidamente cadastrados, que poderão comprar a produção por um preço mais convidativo; inserindo-os, assim, no seu negócio, demonstrando que aquele seguimento social tem compromisso social, melhorando sua imagem com os consumidores em geral, em especial aqueles que exigem do empresariado uma retribuição social pelos dividendos obtidos. Ademais, com a utilização dessa técnica, o detento terá acesso ao alimento sem adição de produtos que possam comprometer sua saúde. De 
acordo com o art. $1^{\mathrm{o}}$, III, combinado com o art. 170 da CF, o cumprimento da pena passa a respeitar piamente a dignidade da pessoa humana, com a valorização inata do ser humano, inobstante denota a função precípua do Estado, no que concerne à ordem econômica de estabelecer um desenvolvimento da economia enfatizando e valorizando o trabalho humano, assegurando uma coexistência digna entre a justiça social, proteção ambiental e economia.

\section{Biografia do Autor}

\section{Alexandre Coutinho Pagliarini, Centro Universitário Internacional (Curitiba, Paraná, Brasil)}

Professor Titular do Mestrado e da Graduação em Direito da UNINTER (Curitiba, Paraná, Brasil). Doutor pela PUC-SP com Pós-Doutorado em Direito pela Universidade de Lisboa. Mestre em Direito pela PUC-SP.

o000-0001-5257-235.9. | alexandrepagliarini@terra.com.br

\section{Flávio Adriano Rebelo Brandão Santos, Universidade Tiradentes (Maceió, Alagoas, Brasil)}

Mestre em Direitos Humanos pela Universidade Tiradentes (UNIT, Aracaju, Sergipe). Professor da UNIT (Maceió, Alagoas), da Faculdade Sete de Setembro (Paulo Afonso/BA) e da Sociedade de Ensino do Nordeste (SEUNE).

o000-0002-5047-7-9799. | rebeloflavioadvogado@hotmail.com

\section{Arthur Augusto Garcia, Centro Universitário Internacional (Curitiba, Paraná, Brasil)}

Professor da Pós-Graduação lato sensu do Centro Universitário Internacional UNINTER (Curitiba, Paraná, Brasil). Mestrando em Direito na linha Jurisdição e Processo na Contemporaneidade na UNINTER. Bacharel em Direito pela PUCPR.

o000-0003-477-9.7-8682 | arthur.brambillaa@gmail.com

\section{Referências}

ALEXY, Robert. Teoria dos direitos fundamentais. São Paulo: Malheiros Editores, 2008.

ANTUNES, Paulo de Bessa. Direito ambiental. 15. ed. São Paulo: Atlas, 2013.

BONAVIDES, Paulo. Curso de direito constitucional. 28. ed. São Paulo: Malheiros, 2013.

BUCCI, Maria Paula Dallari (Org.). Políticas públicas: reflexões sobre o conceito jurídico. São Paulo: Saraiva, 2006.

BURSZTYN, Maria Augusta; BURSZTYN, Marcel. Fundamentos de política e gestão ambiental: caminhos para sustentabilidade. Rio de Janeiro: Garamond, 2012. 
CANOTILHO, José Joaquim Gomes. O princípio da sustentabilidade como princípio estruturante do direito constitucional. Revista de Estudos Politécnicos Polytechnical Studies Review, v. VIII, n. 13, 2010. Disponível em:

[www.scielo.oces.mctes.pt/pdf/tek/n13/n13a02.pdf]. Acesso em: 24.04.2014.

CARRAZZA, Roque Antônio. Curso de direito tributário. 24. ed. São Paulo: Malheiros, 2008.

COELHO, Carla Jeane Helfemsteller. Planejamento ambiental e gestão administrativa. In: COELHO, Carla Jeane Helfemsteller; MELO, Maria das Dores de Vasconcelos Cavalcanti (Org.). Saberes e fazeres da Mata Atlântica do Nordeste: lições para uma gestão participativa. Recife: Associação para Proteção da Mata Atlântica do Nordeste (AMANE), 2010.

COMPARATO, Fábio Konder. Para viver a democracia. São Paulo: Brasiliense, 1990.

DIAMANDIS, Peter; KOTLER, Steven. Abundância: o futuro é melhor do que você imagina. São Paulo: HSM Editora, 2012.

DESPOMMIER, Dickson. The vertical farm: Feeding the World in the 21st Century. Chicago: ST Martins Press, 2010.

GIDDENS, Anthony. A terceira via: reflexões sobre o impasse político atual e futuro da social-democracia. Rio de Janeiro: Record, 1998.

GRAU, Eros. A ordem econômica na Constituição de 1988. 2. ed. São Paulo: Ed. RT, 1995.

HENRIQUEZ, Élcio Fiori. Os benefícios fiscais no direito financeiro e orçamentário: o gasto tributário no direito brasileiro. São Paulo: Quartier Latin, 2010.

MELLO, Marcus Bernardes de. Teoria do fato jurídico: plano da existência. São Paulo: Saraiva, 2013.

MENDES, Gilmar; COELHO, Inocêncio Mártires; BRANCO, Paulo Gustavo Gonet. Curso de Direito Constitucional. 2. ed. Brasília: Instituto Brasiliense de Direito Público; São Paulo: Saraiva, 2008.

PAGLIARINI, Alexandre Coutinho; BASTOS, Juliana Cardoso Ribeiro. Uma interpretação constitucional sobre a relação entre economia e direito ambiental. Revista de Direito da Mackenzie, [S.l.], v. 5, p. 37-52, 2011.

PAGLIARINI, Alexandre Coutinho. Teoria geral e crítica do direito constitucional e internacional dos direitos humanos. In: PAGLIARINI, Alexandre Coutinho; DIMOULIS, Dimitri (Coord.). Direito constitucional internacional dos direitos humanos. Belo Horizonte: Fórum, 2012.

PFERSMANN, Otto. Positivismo jurídico e justiça constitucional no século XX. São Paulo: Saraiva, 2014. 
SABBAG, Eduardo de Moraes. Manual de direito tributário. São Paulo: Saraiva, 2009.

SACHS, Ignacy. Caminhos para o desenvolvimento sustentável. Rio de Janeiro: Garamond, 2000.

SANTILLI, Juliana. Socioambientalismo e novos direitos: proteção jurídica da diversidade biológica e cultural. São Paulo: Petrópolis, 2005.

SARLET, Ingo Wolfgang. Dignidade da pessoa humana e direitos fundamentais na Constituição de 1988. 4. ed. Porto Alegre: Livraria do Advogado, 2006.

SCAFF, Fernando Facury. Tributação e políticas públicas: o ICMS ecológico. In: TORRES, Heleno Taveira (Org.). Direito tributário ambiental. São Paulo: Malheiros, 2005.

SILVA, Geraldo Eulálio do Nascimento. Direito ambiental internacional. 2. ed. Rio de Janeiro: Thex, 2002.

TAVARES, André Ramos. Direito constitucional econômico. São Paulo: Método, 2003.

WINTER, Gerd. A natureza jurídica dos princípios ambientais em direito internacional, direito da Comunidade Européia e direito nacional. In: KISHI, Sandra Akemi Shimada; SILVA, Solange Teles da; SOARES, Inês Virginia Prado. Desafios do direito ambiental no século XXI. São Paulo: Malheiros, 2005.

WOLKMER, Antonio Carlos. Novos pressupostos para a temática dos direitos humanos. In: FLORES, Joaquín Herrera; RUBIO, David Sánchez; CARVALHO, Salo de. Direitos humanos e globalização: fundamentos e possibilidades desde a teoria crítica. 2. ed. Dados eletrônicos. Porto Alegre: EDIPUCRS, 2010.

Legislação

BRASIL. Constituição da República Federativa do Brasil. Brasília, 05.10.1988. Disponível em: [www.planalto.gov.br/ccivil_03/constituicao/constituicao.htm]. Acesso em: 11.12.2019.

BRASIL. Lei Complementar 101, de 04.05.2000 (LGL2000211). Estabelece normas de finanças públicas voltadas para a responsabilidade na gestão fiscal e dá outras providências. Disponível em: [www.planalto.gov.br/ccivil_o3/leis/lcp/lcp101.htm]. Acesso em: 03.12.2019.

BRASIL. Lei 7.210, de 11.07.1984 (LGL198414). Institui a Lei de Execuções Penais. Disponível em: [www.planalto.gov. br/ccivil/leis/L10257.htm]. Acesso em: 11.12.2019.

BRASIL. Lei 10.257, de 10.07.2001 (LGL2001296). (Estatuto da Cidade) Regulamenta os arts. 182 e 183 da Constituição Federal, estabelece diretrizes gerais da política urbana e dá outras providências. Disponível em: [www.planalto.gov. br/ccivil/leis/L10257.htm].

Acesso em: 11.12.2019. 
BRASIL. Lei 13.465, de 11.07.2017 (LGL20175906). Disponível em:

[www.planalto.gov.br/ccivil_03/_ato2015-2018/2017/lei/l13465.htm]. Acesso em: 12.12.2019.

\section{Publicado}

2021-12-15

\section{Como Citar}

PAGLIARINI, A. C.; SANTOS, F. A. R. B.; GARCIA, A. A. Infraestrutura, fazendas horizontais e pena sustentável: alternativas para aplicação do regime semiaberto: Infrastructure, horizontal farms and sustainable penalty: alternatives for applying the semi-open regime. Revista de Direito Administrativo e Infraestrutura | RDAI, São Paulo: Thomson Reuters - Livraria RT, v. 5, n. 19, p. 215-232, 2021. DOI: 10.48143/rdai.19.acp. Disponível em: https://rdai.com.br/index.php/rdai/article/view/420. Acesso em: 7 fev. 2022.

\section{Edição}

v.5‥ 19_(2021).

\section{Seção}

Atividade de Infraestrututra

\section{Licença}

\section{cc) (1) $(9)$}

Este trabalho está licenciado sob uma licença Creative Commons Attribution-

NonCommercial-NoDerivatives 4.0 International License.

(CC BY-NC-ND).

Este é um resumo (e não um substituto) da licença

Regras para publicação

Direitrizes Editoriais

Direitos e Deveres

Errata e Retratação

Preservação e Plagiarismo

Revisão e Avaliaçãão 
